\title{
Impact of obstructive sleep apnoea on diastolic function
}

\author{
Rolf Wachter*,f, Lars Lüthje ${ }^{\star, f}$, Daniela Klemmstein*, Claus Lüers*, \\ Raoul Stahrenberg*, Frank Edelmann*, Volker Holzendorf ${ }^{\mp}$, Gerd Hasenfuß*, \\ Stefan Andreas ${ }^{+, * *}$ and Burkert Pieske ${ }^{\star, \S, \star *}$
}

ABSTRACT: We investigated whether obstructive sleep apnoea (OSA) independently affects diastolic function in a primary care cohort of patients with cardiovascular risk factors.

378 study participants with risk factors for diastolic dysfunction were prospectively included and a polygraphy was performed in all patients. Diastolic dysfunction was assessed by comprehensive echocardiography including tissue Doppler. Sleep apnoea was classified according to apnoea/ hypopnoea index $(\mathrm{AHI})$ as none $\left(\mathrm{AHI}<\mathbf{5}\right.$ events $\left.\cdot \mathrm{h}^{-1}\right)$, mild $\left(\mathrm{AHI} \leqslant \mathbf{5}\right.$ to $<\mathbf{1 5}$ events $\left.\cdot \mathrm{h}^{-1}\right)$ or moderateto-severe $\left(A H I \geqslant 15\right.$ events $\left.\cdot h^{-1}\right)$.

Patients with central sleep apnoea $(n=14)$ and patients with previously diagnosed sleep apnoea $(n=12)$ were excluded. In the remaining 352 subjects, $21.6 \%$ had an $A H I \geqslant 15$ events $\cdot h^{-1}$. The prevalence of diastolic dysfunction increased with the severity of sleep apnoea from $44.8 \%$ (none) to $56.8 \%$ (mild) to $69.7 \%$ (moderate-to-severe sleep apnoea) $(p=0.002)$. The degree of diastolic dysfunction also increased with sleep apnoea severity $(p=0.004)$. In univariate regression analysis, age, desaturation index, $\mathrm{AHI}$, cardiac frequency, angiotensin receptor 1 antagonist therapy, body mass index (BMI) and left ventricular mass were associated with diastolic dysfunction. In multivariate regression analysis, only age, $\mathrm{BMI}, \mathrm{AHI}$ and cardiac frequency were independently associated with diastolic dysfunction.

Moderate-to-severe OSA is independently associated with diastolic dysfunction in patients with classical risk factors for diastolic dysfunction.

\section{KEYWORDS: Diastolic function, echocardiography, sleep apnoea}

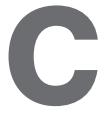
hronic heart failure is a substantial, stillgrowing epidemic burden for western societies [1]. About half of the patients presenting with the clinical syndrome of heart failure have a normal left ventricular ejection fraction (LVEF) [2, 3]. These cases are defined as heart failure with preserved ejection fraction (HFprEF) and left ventricular (LV) diastolic dysfunction is considered to be a common underlying pathology [4]. HFprEF typically occurs in the elderly and is associated with classical risk factors, such as arterial hypertension [5], diabetes mellitus [6] and atrial fibrillation [7]. The prognosis of HFprEF patients, once hospitalised for heart failure, is similarly poor as in heart failure with reduced ejection fraction, but has, in contrast to heart failure with reduced ejection fraction, not improved during the last decades [2, 3]. Convincing therapeutic strategies for HFprEF other than risk factor control are lacking.

In recent years, intensive research has revealed multiple negative consequences of obstructive sleep apnoea (OSA) on the cardiovascular system
$[8,9]$. The pathophysiological interaction between OSA and cardiovascular disease is complex and comprises sympathetic activation, inflammation, oxidative stress, endothelial dysfunction and clock gene dysfunction [9-11]. OSA is an independent risk factor for arterial hypertension [12-14]. Epidemiological data demonstrate that OSA has prognostic implications for cardiovascular morbidity and mortality (for a review see [8]). Uncontrolled studies indicate that OSA therapy improves this elevated cardiovascular risk [9].

Furthermore, in a randomised, placebo-controlled, double-blind study in selected normotensive OSA patients without cardiovascular disease, continuous positive airway pressure (CPAP) therapy resulted in improved diastolic function [15]. The potential of CPAP therapy to reverse functional and structural remodelling of the heart has been confirmed in several studies [16-19]. However, it is currently unclear whether OSA is an independent risk factor for diastolic dysfunction and diastolic heart failure. Smaller studies in OSA patients revealed that oxygen desaturation $[20,21]$
AFFILIATIONS

*Dept of Cardiology and

Pneumology, University of Göttingen, Göttingen,

\#Dept of Internal Medicine, Cardiology, University of Marburg, Marburg,

"Center for Clinical Trials, University of Leipzig, Leipzig, and +Lungenfachklinik Immenhausen, Immenhausen, Germany. ${ }^{5}$ Dept of Cardiology, Medical University of Graz, Graz, Austria. ${ }^{f}$ These authors are joint first authors. **These authors are joint last authors.

CORRESPONDENCE

S. Andreas

Lungenfachklinik Immenhausen

Robert-Koch-Str. 3

34376 Immenhausen

Kr. Kassel

Germany

E-mail: sandreas@lungenfachklinik-

immenhausen.de

Received:

Dec 122011

Accepted after revision:

April 232012

First published online:

July 122012

European Respiratory Journa Print ISSN 0903-1936 Online ISSN 1399-3003 
or obstructive apnoeas [22] were associated with abnormalities of diastolic filling. However, such an association could not be confirmed in a large cross-sectional study including $>500$ patients with OSA [23].

We hypothesised that hitherto undiagnosed OSA is independently associated with diastolic dysfunction. Therefore, we assessed sleep breathing patterns and diastolic function in a large, prospective cohort of noncardiac primary care patients with cardiovascular risk factors.

\section{METHODS}

\section{Subjects}

Patient recruitment has previously been described in detail [6]. The German competence network heart failure (www.knhi.de) is a publicly funded multicentre initiative for heart failure research. We recruited a total of 1,732 patients of general practitioners (GPs) at risk for heart failure (American Heart Association/ American College of Cardiology stage A or B) or with signs/ symptoms of heart failure (stage $\mathrm{C}$ ) into the prospective longitudinal Diastolic-Chronic Heart Failure (DIAST-CHF) study, which is part of the network.

Inclusion criteria were the following: 1) age 50-85 yrs; and 2) at least one risk factor for diastolic dysfunction (hypertension, diabetes, sleep apnoea, atherosclerotic disease or signs/symptoms of heart failure).

The only exclusion criteria were inability to participate or consent or severe concomitant diseases.

Patients with heart failure were also included as part of the inclusion criteria of DIAST-CHF. As the impact of sleep apnoea may vary in patients with and without heart failure, analyses were repeated after exclusion of heart failure patients (see results).

Candidates were identified by a software-based search strategy of the patient databases of participating GP's computer systems. Suitable patients were invited to participate by their GP. All those who consented (52\%) underwent a comprehensive noninvasive diagnostic workup at baseline, including patient history and physical examination, laboratory analyses, ECG, body plethysmography, comprehensive echocardiography, 6min walk test and several psychosocial and quality-of-life questionnaires.

A substudy with polygraphy was offered to participants at the study site, Göttingen, Germany. These participants were randomly selected from the total local cohort (first patient per day).

The study complies with the Declaration of Helsinki, the protocol was approved by the responsible ethics committee (Universitätsmedizin Göttingen, Göttingen, Germany) and all patients gave written informed consent.

\section{Polygraphy}

Over an inclusion period of 18 months, ambulatory investigation for sleep-disordered breathing was performed with the Stardust II Sleep recorder (Philips Respironics, Best, the Netherlands), as desribed previously [24]. The median time between the echocardiographic examination and the sleep recorder study was 11.5 days (range 6-29 days). Oxygen saturation and cardiac frequency were recorded by fingertip pulse oximetry. Airflow was monitored by nasal pressure, while thoracic wall motion was measured by an inductive plethysmographic belt wrapped tightly around the chest. Analysis was conducted manually by two of the investigators (L. Lüthje and D. Klemmstein) blinded to the patient's echocardiographic and laboratory data using custom-software provided by the manufacturer. Respiratory events needed a minimum duration of $10 \mathrm{~s}$ for analysis. An apnoea was considered obstructive when nasal flow was absent in the presence of thoracic movements, and central when movements were also absent. Hypopnoeas were defined as $a \geqslant 50 \%$ reduction in tidal volume and $a \geqslant 3 \%$ desaturation from the baseline value as compared with the preceding signals. Based on the apnoea/hypopnoea index (AHI) for time in bed (recording time), patients were classified into three groups: 1 ) no sleep apnoea (AHI $<5$ events $\left.\cdot h^{-1}\right) ; 2$ ) mild sleep apnoea (AHI 5-14 events $\cdot h^{-1}$ ); and 3) moderate-tosevere sleep apnoea $\left(\mathrm{AHI} \geqslant 15\right.$ events $\left.\cdot \mathrm{h}^{-1}\right)$.

\section{Echocardiography}

Comprehensive echocardiography, including careful evaluation of diastolic function, was performed on a Hewlett-Packard Sonos 5500 (Hewlett-Packard, Andover, MA, USA) according to the guidelines of the American Society of Echocardiography. Briefly, transmitral peak velocities of early (E) and late or atrial (A) inflow and E wave deceleration time were recorded at the tips of the mitral valve leaflets. Isovolumetric relaxation time was obtained in the apical five chamber view. Peak tissue velocities were derived by tissue Doppler analysis at the medial and lateral margin of the mitral annulus for early $\left(\mathrm{e}^{\prime}\right)$ and late $\left(\mathrm{a}^{\prime}\right)$ diastolic inflow. E/ $\mathrm{e}^{\prime}$ was calculated using the mean of medial and lateral $\mathrm{e}^{\prime}$. Left atrial volume was calculated by the ellipsoid formula as previously described [25] and left atrial volume index (LAVI) was calculated as left atrial volume indexed to body surface area. Left ventricular end-diastolic and end-systolic volumes and LVEF were measured by the modified Simpson's method. Left ventricular mass (LVM in grammes) was calculated by the Devereux formula [26] and was normalised for body surface area and additionally expressed as LVM index in $\mathrm{g} \cdot \mathrm{cm}^{-2}$.

Diastolic dysfunction was classified according to recent recommendations [27] as follows: 1) normal diastolic function $\left(\mathrm{e}^{\prime}\right.$ (lateral) $>10 \mathrm{~cm} \cdot \mathrm{s}^{-1}, \mathrm{e}^{\prime}$ (medial) $>8 \mathrm{~cm} \cdot \mathrm{s}^{-1}$ and LAVI $<34 \mathrm{~mL} \cdot \mathrm{m}^{-2}$ ); 2) mild diastolic dysfunction (E/A $<0.8, \mathrm{e}^{\prime}$ (lateral) $<10 \mathrm{~cm} \cdot \mathrm{s}^{-1}$ and $\mathrm{e}^{\prime}$ (medial) $<8 \mathrm{~cm} \cdot \mathrm{s}^{-1}$ ); and 3) diastolic dysfunction with elevated filling pressures $\left(E / \mathrm{e}^{\prime}>13 \mathrm{~cm} \cdot \mathrm{s}^{-1}\right.$ or $\mathrm{E} / \mathrm{e}^{\prime}>9$ and LAVI $>34 \mathrm{~mL} \cdot \mathrm{m}^{-2}$ ).

Diastolic function could not be classified in two study participants with atrial fibrillation who fulfilled neither the definition for normal diastolic function nor for diastolic dysfunction with elevated filling pressures, because mild diastolic dysfunction could not be diagnosed because of a missing A wave in atrial fibrillation.

\section{Calculations and statistical analyses}

Data are presented as mean $\pm \mathrm{SD}$, if variables were normally distributed. Variables not normally distributed are expressed as median (interquartile range) for continuous variables or absolute number (percentage) for categorical variables. Continuous data were compared by ANOVA (followed by Turkey's post hoc test) or the Mann-Whitney U-test; categorical data were compared by the Chi-squared or Kruskal-Wallis test. 
To assess the association between two continuous variables, bivariate correlation analysis was used. To analyse which variables are associated with diastolic dysfunction, univariate analyses were performed separately for each variable using binary logistic regression analysis. The variables that showed a statistically different baseline characteristic between the no OSA and the OSA groups or which have been described in the literature as causes of diastolic dysfunction were included in the analysis. Variables with a p-value $\leqslant 0.10$ in univariate analyses or well-known causes of diastolic dysfunction were candidates for multivariable logistic regression analysis with stepwise inclusion ( $p<0.05$ for entry, not taken out if $\mathrm{p}<0.10)$. Statistical analyses were conducted with PASW Statistics 18.0 software (SPSS Inc., Chicago, IL, USA). A p-value $<0.05$ was considered statistically significant.

\section{RESULTS}

\section{Patient characteristics}

402 out of 1,283 study participants at the study site Göttingen were offered to participate in this substudy and 378 (94\%) agreed. Compared with the overall 1,283 study participants, those included in this substudy were slightly younger $(66.2 \pm 7.0$ versus $67.3 \pm 8.1$ yrs, $\mathrm{p}<0.001$ ), but sex, body mass index $(\mathrm{BMI})$ and weight were not significantly different. We excluded patients with predominately central apnoeas $(n=14)$ and those with a known history of sleep apnoea $(n=12)$ from further analysis. Thus, 352 patients were included in the final analysis.

Baseline characteristics of the three respiratory pattern groups are shown in table 1. 21 patients had a severe OSA (AHI $>30$ events $\left.\cdot h^{-1}\right)$. As a first finding, OSA was highly prevalent in this cardiovascular risk groups: 136 (39\%) had no OSA, 140 (40\%) had mild OSA, and $76(22 \%)$ had moderate-to-severe OSA.

Patients with OSA were older, less often female, more obese, and tended to have higher systolic blood pressure values and more heart failure than those without OSA. Pulmonary function did not differ between groups.

\section{Polygraphy}

Standard physical and clinical parameters obtained during polysomnography are presented in table 2 . The median (interquartile range) recording time was 461 (415-510) $\mathrm{min}$ and did

TABLE 1 Demographics of the study participants, according to sleep apnoea severity

\begin{tabular}{|c|c|c|c|c|}
\hline & $A H I<5$ events $\cdot h^{-1}$ & AHI 5-14 events $\cdot h^{-1}$ & $A H I \geqslant 15$ events $\cdot h^{-1}$ & $\mathrm{p}$-value \\
\hline Subjects $\mathrm{n}$ & 136 & 140 & 76 & \\
\hline Age yrs & $64 \pm 7$ & $67 \pm 6^{*}$ & $68 \pm 8^{*}$ & 0.001 \\
\hline Female \% & 57.4 & 54.3 & 36.8 & 0.012 \\
\hline $\mathrm{BMI} \mathrm{kg} \cdot \mathrm{m}^{-2}$ & $28.1 \pm 4.6$ & $28.6 \pm 4.0$ & $30.1 \pm 5.0^{*}$ & 0.011 \\
\hline Cardiac frequency beats $\cdot \mathrm{min}^{-1}$ & $71 \pm 12$ & $71 \pm 12$ & $69 \pm 13$ & 0.499 \\
\hline Atrial fibrillation & 1.5 & 0.7 & 1.3 & 0.759 \\
\hline Hypertension & 87.5 & 85.0 & 93.4 & 0.195 \\
\hline Diabetes & 14.7 & 16.4 & 14.5 & 0.899 \\
\hline Hyperlipidaemia & 41.9 & 34.3 & 47.4 & 0.147 \\
\hline Smoking pack-yrs & $20 \pm 17$ & $21 \pm 21$ & $24 \pm 25$ & 0.642 \\
\hline \multicolumn{5}{|l|}{ Body plethysmography } \\
\hline FEV $1 \%$ pred & $92 \pm 17$ & $93 \pm 18$ & $92 \pm 14$ & 0.752 \\
\hline Vital capacity \% pred & $88 \pm 14$ & $90 \pm 16$ & $88 \pm 14$ & 0.530 \\
\hline Residual volume \% pred & $106 \pm 33$ & $109 \pm 30$ & $104 \pm 27$ & 0.518 \\
\hline Total lung capacity \% pred & $93 \pm 14$ & $95 \pm 13$ & $92 \pm 14$ & 0.284 \\
\hline Total airway resistance $\mathrm{kPa} \cdot \mathrm{L}^{-1} \cdot \mathrm{s}^{-1}$ & $0.36 \pm 0.19$ & $0.34 \pm 0.14$ & $0.33 \pm 0.15$ & 0.394 \\
\hline \multicolumn{5}{|l|}{ Medication } \\
\hline ACE inhibition & 41.9 & 45.7 & 44.7 & 0.809 \\
\hline AT1 antagonist & 10.3 & 11.4 & 31.6 & $<0.001$ \\
\hline$\beta$-blockers & 41.9 & 45.7 & 55.3 & 0.171 \\
\hline
\end{tabular}

Data are presented as mean \pm SD or \%, unless otherwise stated. AHI: apnoea/hypopnoea index; BMI: body mass index; FEV1: forced expiratory volume in 1 s; \% pred: \% predicted; ACE: angiotensin-converting enzyme; AT1: angiotensin receptor $1 .{ }^{\star}: p<0.05$ versus $A H I<5$ events $\cdot h^{-1}$. 
TABLE 2 Respiratory data according to sleep apnoea severity

\begin{tabular}{|c|c|c|c|c|}
\hline & $A H I<5$ events $\cdot h^{-1}$ & AHI 5-14 events $\cdot h^{-1}$ & $A H I \geqslant 15$ events $\cdot h^{-1}$ & p-value \\
\hline Subjects n & 136 & 140 & 76 & \\
\hline Average $\mathrm{O}_{2}$ saturation \% & 95 (93-95) & 94 (93-95) & 94 (93-95) & 0.003 \\
\hline Desaturation index \% & $5(2-9)$ & $12(7-17)$ & $20(15-34)$ & $<0.001$ \\
\hline Minimal $\mathrm{O}_{2}$ saturation $\%$ & $82(76-87)$ & $81(74-85)$ & 79 (73-83) & 0.037 \\
\hline
\end{tabular}

not differ between groups. Desaturation index, minimal oxygen saturation and Epworth Sleepiness Scale score gradually worsened with increasing AHI frequency.

\section{Echocardiographic parameters}

Table 3 summarises echocardiographic parameters of cardiac function and remodelling. Systolic function was normal (mean ejection fraction $59 \pm 10 \%$ ) and did not differ between groups. However, adverse LV remodelling was more pronounced in
OSA patients: LV end-diastolic diameter was slightly larger in moderate-to-severe OSA, LV volumes tended to be higher and all parameters of LV hypertrophy gradually increased with increasing AHI. Traditional parameters of diastolic function showed no association with OSA, but tissue Doppler-derived indices of diastolic dysfunction showed significant differences: $\mathrm{e}^{\prime}$ was reduced in OSA, whereas $\mathrm{E} / \mathrm{e}^{\prime}$ as a central parameter of diastolic dysfunction and estimate of LV end-diastolic pressure significantly increased with increasing severity of OSA.

\section{TABLE 3 Results according to sleep apnoea severity}

\begin{tabular}{|c|c|c|c|c|}
\hline & AHI $<5$ events $\cdot h^{-1}$ & AHI 5-14 events $\cdot h^{-1}$ & $A H I \geqslant 15$ events $\cdot h^{-1}$ & p-value \\
\hline Subjects $\mathbf{n}$ & 136 & 140 & 76 & \\
\hline 6-min walking distance $\mathrm{m}$ & $560 \pm 81$ & $551 \pm 84$ & $535 \pm 87$ & 0.134 \\
\hline \multicolumn{5}{|l|}{ Echocardiography } \\
\hline Ejection fraction $\%$ of respective population & $59 \pm 8$ & $60 \pm 11$ & $58 \pm 9$ & 0.268 \\
\hline LVPW mm & $10.8 \pm 1.4$ & $11.2 \pm 1.4^{*}$ & $11.3 \pm 1.4^{*}$ & 0.006 \\
\hline Left ventricular mass g & $220 \pm 65$ & $230 \pm 58$ & $254 \pm 76^{\star * \#}$ & 0.001 \\
\hline Left ventricular mass index $\mathrm{g} \cdot \mathrm{m}^{-2}$ & $113 \pm 26$ & $119 \pm 26$ & $125 \pm 29$ & 0.012 \\
\hline LVEDD mm & $50 \pm 6$ & $50 \pm 5$ & $52 \pm 7^{\star, \#}$ & 0.015 \\
\hline Left ventricular end-systolic volume $\mathrm{mL}$ & $41 \pm 20$ & $39 \pm 15$ & $45 \pm 27$ & 0.166 \\
\hline Left ventricular end-systolic volume index $\mathrm{mL} \cdot \mathrm{m}^{-2}$ & $21 \pm 9$ & $20 \pm 7$ & $22 \pm 11$ & 0.366 \\
\hline LAVI $\mathrm{mL} \cdot \mathrm{m}^{-2}$ & $24 \pm 8$ & $26 \pm 8$ & $28 \pm 8$ & 0.254 \\
\hline E/A ratio & $1.0 \pm 0.3$ & $1.0 \pm 0.3$ & $1.0 \pm 0.4$ & 0.418 \\
\hline EDCT $\mathrm{ms}$ & $240 \pm 69$ & $257 \pm 76$ & $253 \pm 70$ & 0.153 \\
\hline IVRT ms & $98 \pm 17$ & $100 \pm 19$ & $96 \pm 19$ & 0.291 \\
\hline $\mathrm{e}^{\prime}$ medial & $5.9 \pm 1.7$ & $5.6 \pm 1.5$ & $5.6 \pm 1.6$ & 0.151 \\
\hline $\mathrm{e}^{\prime}$ lateral & $8.3 \pm 2.6$ & $7.8 \pm 2.2$ & $7.4 \pm 2.1^{*}$ & 0.021 \\
\hline E/e' mean ratio & $11.0 \pm 3.6$ & $11.7 \pm 3.5$ & $12.7 \pm 5.3^{*}$ & 0.011 \\
\hline
\end{tabular}


The presence of diastolic dysfunction was significantly associated with OSA. While $45 \%$ of classical risk patients for abnormal diastolic function with an AHI $<5$ events $\cdot h^{-1}$ had echocardiographic evidence of diastolic dysfunction, this number increased to $57 \%$ in mild and $70 \%$ in moderate-to-severe OSA patients with a comparable cardiovascular risk factor background $(p=0.004$ for comparison of degrees of diastolic dysfunction with degrees of sleep apnoea and $\mathrm{p}=0.002$ for comparison of presence of diastolic dysfunction with presence of sleep apnoea). Moreover, diastolic dysfunction was more severe with OSA as shown by an increase in participants with elevated filling pressure (fig. 1). Left atrial volume as a continuous marker of left atrial size significantly correlated with $\mathrm{AHI}(\mathrm{r}=0.259, \mathrm{p}=0.002$; fig. 2). Left atrial volume, to a lesser extent, also correlated with BMI $(\mathrm{r}=0.225, \mathrm{p}<0.001)$ and age $(\mathrm{r}=0.141, \mathrm{p}=0.008)$.

To further substantiate the notion that OSA is associated with diastolic dysfunction, univariate and multivariate regression analyses were performed.

In univariate analysis, age, AHI, desaturation index, cardiac frequency, BMI, therapy with Angiotensin receptor 1 antagonists and LVM were associated with diastolic dysfunction (table 4). These six variables as well as hypertension and diabetes were tested in a multivariate model. Only age, BMI, $\mathrm{AHI}$ and cardiac frequency were independently associated with diastolic dysfunction and entered into the final model (table 5). If patients with systolic dysfunction (ejection fraction $<50 \%$ ) and/or heart failure were excluded, the results remained similar apart from the fact that BMI was no longer significant $(p=0.099)$.

\section{DISCUSSION}

In this large cross-sectional cohort of patients with risk factors for diastolic dysfunction, moderate-to-severe OSA was independently associated with impaired LV filling. In our cohort,
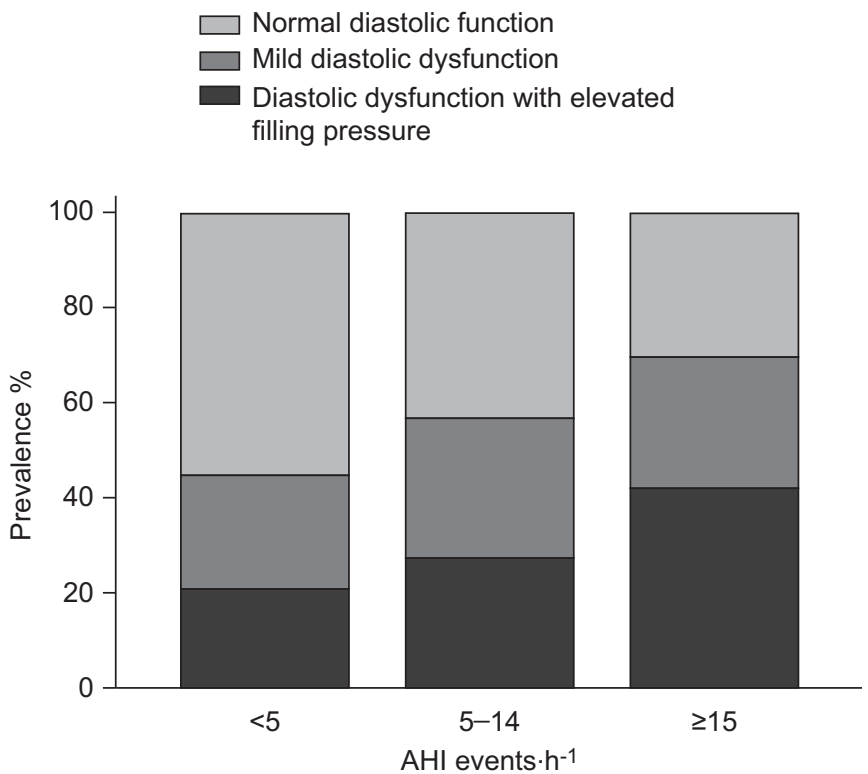

FIGURE 1. Prevalence of diastolic dysfunction according to sleep apnoea severity as measured by the apnoea/hypopnoea index (AHI). $p=0.004$ for the comparison of degrees of diastolic dysfunction to degrees of sleep apnoea (according to the Chi-squared test).

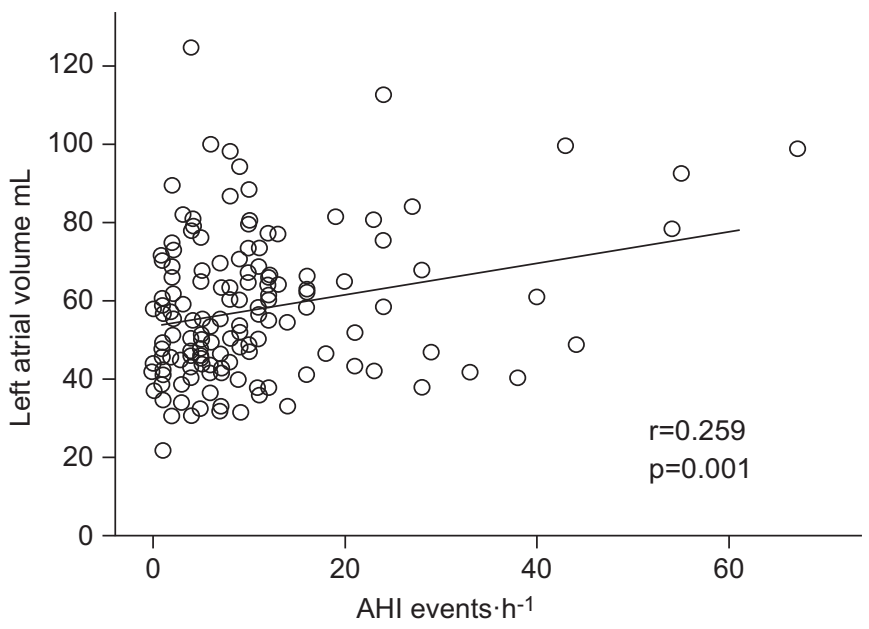

FIGURE 2. Bivariate correlation analysis for the apnoea/hypopnoea index $(\mathrm{AHI})$ and left atrial volume.

$21.6 \%$ of the subjects had an AHI $\geqslant 15$ events $\cdot h^{-1}$, which is higher than in the general population [9], but comparable to populations with heart failure [24], arterial hypertension [28] or coronary artery disease [10], as reported previously. Our data confirm the established impact of cardiac frequency, BMI and LVM on diastolic function. We found a high prevalence of diastolic dysfunction, which is probably explained by the inclusion criteria of our study (age $>50 \mathrm{yrs}$, at least one risk

\begin{tabular}{|c|c|c|c|}
\hline $\begin{array}{l}\text { Univariate regr } \\
\text { predictors for }\end{array}$ & $\begin{array}{l}\text { ression } \\
\text { diastoli }\end{array}$ & $\begin{array}{l}\text { nalysis to identif } \\
\text { dysfunction }\end{array}$ & \\
\hline Variable & $p$-value ${ }^{\#}$ & OR $(95 \% \mathrm{Cl})$ & $R^{2 \pi}$ \\
\hline Age yrs & $<0.001$ & $1.136(1.093-1.180)$ & 0.193 \\
\hline Female & 0.663 & $0.910(0.597-1.389)$ & 0.001 \\
\hline $\begin{array}{c}\text { Sleep apnoea (AHI } \\
\geqslant 15 \text { events } \cdot h^{-1} \text { ) }\end{array}$ & 0.004 & $2.221(1.290-3.827)$ & 0.033 \\
\hline AHI events $\cdot h^{-1}$ & 0.001 & $1.041(1.017-1.065)$ & 0.052 \\
\hline Desaturation index \% & 0.003 & $1.031(1.011-1.052)$ & 0.003 \\
\hline Hypertension & 0.487 & $1.257(0.659-2.397)$ & 0.002 \\
\hline Diabetes & 0.149 & $1.563(0.853-2.865)$ & 0.008 \\
\hline Coronary artery disease & 0.092 & $1.676(0.919-3.058)$ & 0.011 \\
\hline Left ventricular mass $\mathbf{g}$ & 0.021 & $1.004(1.001-1.007)$ & 0.021 \\
\hline LVEDD & 0.442 & $1.015(0.977-1.054)$ & 0.002 \\
\hline BMI $\mathbf{k g} \cdot \mathrm{m}^{-2}$ & 0.005 & $1.075(1.022-1.130)$ & 0.032 \\
\hline Cardiac frequency beats $\mathrm{min}^{-1}$ & 0.010 & $1.024(1.006-1.042)$ & 0.026 \\
\hline Systolic blood pressure $\mathrm{mmHg}$ & 0.196 & $1.007(0.996-1.018)$ & 0.006 \\
\hline Diastolic blood pressure $\mathrm{mmHg}$ & 0.391 & $0.992(0.974-1.010)$ & 0.003 \\
\hline AT1 antagonists & 0.032 & $1.966(1.060-3.647)$ & 0.018 \\
\hline Calcium channel blockers & 0.718 & $0.925(0.606-1.412)$ & 0.000 \\
\hline Diuretics & 0.044 & $1.547(1.012-2.365)$ & 0.016 \\
\hline Loop diuretics & 0.181 & $1.809(0.759-4.311)$ & 0.007 \\
\hline Thiazide & 0.063 & $1.501(0.979-2.300)$ & 0.013 \\
\hline Other diuretics & 0.233 & $1.828(0.678-4.925)$ & 0.006 \\
\hline Number of antihypertensives & 0.080 & $1.161(0.982-1.372)$ & 0.012 \\
\hline
\end{tabular}

AHI: apnoea/hypopnoea index; LVEDD: left ventricular end-diastolic diameter; BMI: body mass index; AT1: angiotensin receptor $1 .{ }^{*}$ : univariate analysis; " Nagelkerkes $R^{2}$. 


\begin{tabular}{|c|c|c|c|}
\hline \multirow[t]{2}{*}{ TABLE 5} & \multicolumn{3}{|c|}{$\begin{array}{l}\text { Multivariate regression analysis to identify } \\
\text { predictors for diastolic dysfunction }\end{array}$} \\
\hline & & OR (95\% Cl) & p-value \\
\hline \multicolumn{2}{|l|}{ Age yrs } & $1.136(1.090-1.185)$ & $<0.001$ \\
\hline \multicolumn{2}{|c|}{$A H I$ events $\cdot h^{-1}$} & $1.038(1.010-1.067)$ & 0.008 \\
\hline \multicolumn{2}{|l|}{ BMI $\mathbf{k g} \cdot \mathrm{m}^{-2}$} & $1.073(1.012-1.138)$ & 0.018 \\
\hline \multicolumn{2}{|c|}{ Cardiac frequency beats $\mathrm{min}^{-1}$} & $1.038(1.017-1.059)$ & $<0.001$ \\
\hline
\end{tabular}

factor for diastolic dysfunction, etc.). We did not find an association between diabetes and diastolic function [29], which may be explained by the relatively small number of patients included with a pre-diagnosed diabetes $(n=55)$.

\section{OSA and diastolic dysfunction}

Our finding of an association of OSA with diastolic dysfunction is supported by other studies [18, 20-22, 30], although these studies are limited by a small sample size of between 20 and 68 participants. In a cohort of $>500$ patients, NiROUMAND et al. [23] did not show an association of OSA with diastolic function. In that study, however, no tissue Doppler data were available and the diagnosis of diastolic dysfunction relied on the E/A ratio only. As the E/A ratio is decreased in stage 1 diastolic dysfunction (impaired relaxation), but pseudonormal in stage 2 diastolic dysfunction, a diagnosis of diastolic dysfunction based on E/A ratio only is not possible and is discouraged by current guidelines. Rather, tissue Doppler is now regarded to be essential for the noninvasive diagnosis and grading of diastolic function [4]. Indeed, it has consistently been shown that the degree of diastolic dysfunction as classified by tissue Doppler is a strong predictor of mortality [31]. Due to this classification problem based on the limited knowledge of assessment of diastolic function at the time of their analysis, NIROUMAND et al. [23] may have missed a substantial subset of patients with diastolic dysfunction in their analysis.

In our cohort, we found an odds ratio of $\sim 2.0$ for the presence of diastolic dysfunction in moderate-to-severe sleep apnoea. This is comparable with the risk association of sleep apnoea and arterial hypertension, heart failure as well as coronary artery disease in previous cross-sectional studies yielding multivariate odds ratios around two [29, 10,32-35]. At present, the mechanisms explaining the relationship between HFprEF and OSA are not well defined. However, negative effects of sleep apnoea on LV structure and function independent of blood pressure are well described. These effects might be related to the autonomic nervous system, clock genes, endothelial dysfunction, inflammation, blood sugar control or oxidative stress $[8,9,11]$. Recently it has been shown that treating OSA not only contributes to an improvement of systolic and diastolic blood pressure, but also effects on lipid levels, glycated haemoglobin levels, BMI and abdominal fat content, all established risk factors for $\operatorname{HFprEF}[4,36]$.

Central sleep apnoea was rare in our cohort $(<4 \%)$, which may be explained by the low prevalence of heart failure with reduced ejection fraction, where central apnoea is much more common $[37,38]$. Nevertheless, recent data also showed a higher prevalence of OSA than central sleep apnoea in heart failure with reduced ejection fraction [24]. Our results are in agreement with BITTER et al. [39], who reported a higher prevalence of OSA $(40 \%)$ than central sleep apnoea $(30 \%)$ in patients suffering from symptomatic HFprEF. Furthermore, CHAN et al. [40] demonstrated in a small study of symptomatic HFprEF a prevalence of sleep-disordered breathing of $55 \%$, with a majority of these patients suffering from OSA. However, in both studies, central sleep apnoea was seen more often than in our study, possibly because our patients were at an earlier stage of cardiac disease. This may be explained by the fact that most of our patients had only diastolic dysfunction, not symptomatic HFprEF as in the above-mentioned papers $[39,40]$. Our results of an independent association of OSA with diastolic dysfunction support the concept of treating OSA to improve diastolic function and to prevent symptomatic HFprEF. Several small studies so far indeed could demonstrate positive effects of CPAP treatment of OSA on diastolic function [15, 19, 41].

\section{Limitations}

We evaluated sleep apnoea by ambulatory polygraphy, not polysomnography. However, different studies investigating the ability of polygraphy to detect sleep-disordered breathing showed a high diagnostic accuracy of the portable recording devices [42-44]. It is unlikely that the additional information on sleep stages given by polysomnography would profoundly modify the results.

The definition and grading of diastolic dysfunction is still a matter of debate and, indeed, various different classifications have been used. We cannot rule out that the results would have been different in other classifications of diastolic dysfunction. We chose to use the recent classification by NAGUEH et al. [27], although classification of cases is often not unequivocal. We retested the hypothesis with another recently published classification [6], and found similar results of an independent association of moderate-to-severe OSA with diastolic dysfunction. In addition, we also analysed well-validated continuous quantitative parameters of diastolic function (e.g. $\mathrm{e}^{\prime}$ and $\left.\mathrm{E} / \mathrm{e}^{\prime}\right)$ that are independent of any classification system for the degree of diastolic dysfunction; these parameters were also negatively affected by sleep apnoea in our study. Summarising these data, we think there is robust evidence to support our findings.

A minority of included patients had heart failure and/or systolic dysfunction. Our results (especially the multivariate analysis) remained unchanged if these patients were excluded. However, the number of patients with heart failure and/or systolic dysfunction was too small to investigate whether the impact of OSA in this subgroup is similar to patients with preserved ejection fraction and without heart failure.

Finally, multivariate analysis can only describe an association, but does not prove cause and effect. However, the results from our large cross-sectional primary care cohort are corroborated by the findings from small but well-controlled randomised trials using CPAP in OSA patients without hypertension or cardiovascular disease [12, 13]. Furthermore, blood pressureindependent negative effects of OSA on the left ventricle are well described as detailed above. 


\section{Summary}

In a large primary care cohort of patients with risk factors for diastolic dysfunction, the presence of moderate-to-severe OSA is independently associated with the prevalence and severity of diastolic dysfunction. This cross-sectional data support small, well-controlled trials in patients without cardiovascular risk factors showing an improvement of diastolic function with CPAP. Thus, it might be inferred that OSA is a promising target for improving diastolic function and consecutively reduce the burden of HFprEF.

\section{SUPPORT STATEMENT}

This work was supported by grants from the German Federal Ministry of Education and Research (German Heart Failure Network, TP 7 (FKZ 01GI0205) and clinical trial programme Aldo-DHF (FKZ 01KG0506)).

\section{STATEMENT OF INTEREST}

None declared.

\section{REFERENCES}

1 Schocken DD, Benjamin EJ, Fonarow GC, et al. Prevention of heart failure: a scientific statement from the American Heart Association Councils on Epidemiology and Prevention, Clinical Cardiology, Cardiovascular Nursing, and High Blood Pressure Research; Quality of Care and Outcomes Research Interdisciplinary Working Group; and Functional Genomics and Translational Biology Interdisciplinary Working Group. Circulation 2008; 117: 2544-2565.

2 Lee DS, Gona P, Vasan RS, et al. Relation of disease pathogenesis and risk factors to heart failure with preserved or reduced ejection fraction: insights from the Framingham Heart Study of the National Heart, Lung, and Blood Institute. Circulation 2009; 119: 3070-3077.

3 Owan TE, Hodge DO, Herges RM, et al. Trends in prevalence and outcome of heart failure with preserved ejection fraction. $N$ Engl J Med 2006; 355: 251-259.

4 Paulus WJ, Tschöpe C, Sanderson JE, et al. How to diagnose diastolic heart failure: a consensus statement on the diagnosis of heart failure with normal left ventricular ejection fraction by the Heart Failure and Echocardiography Associations of the European Society of Cardiology. Eur Heart J 2007; 28: 2539-2550.

5 Pieske B, Wachter R. Impact of diabetes and hypertension on the heart. Curr Opin Cardiol 2008; 23: 340-349.

6 Stahrenberg R, Edelmann F, Mende M, et al. Association of glucose metabolism with diastolic function along the diabetic continuum. Diabetologia 2010; 53: 1331-1340.

7 Lee DS, Gona P, Vasan RS, et al. Relation of disease pathogenesis and risk factors to heart failure with preserved or reduced ejection fraction: insights from the Framingham Heart Study of the National Heart, Lung, and Blood Institute. Circulation 2009; 119: 3070-3077.

8 McNicholas WT, Bonsignore MR, the Management Committee of EU Cost Action B26. Sleep apnoea as an independent risk factor for cardiovascular disease: current evidence, basic mechanisms and research priorities. Eur Respir J 2007; 29: 156-178.

9 Bradley TD, Floras JS. Obstructive sleep apnea and its cardiovascular complications. Lancet 2009; 373: 82-93.

10 Lüthje L, Andreas S. Obstructive sleep apnea and coronary artery disease. Sleep Med Rev 2008; 12: 19-31.

11 Andreas S, Eichele G. Sleep apnoea: time to consider clock genes. Eur Respir J 2008; 32: 1-2.

12 Bazzano LA, Khan Z, Reynolds K, et al. Effect of nocturnal nasal continuous positive airway pressure on blood pressure in obstructive sleep apnea. Hypertension 2007; 50: 417-423.
13 Haentjens P, Van Meerhaeghe A, Moscariello A, et al. The impact of continuous positive airway pressure on blood pressure in patients with obstructive sleep apnea syndrome: evidence from a meta-analysis of placebo-controlled randomized trials. Arch Intern Med 2007; 167: 757-764.

14 Peppard PE, Young T, Palta M, et al. Prospective study of the association between sleep-disordered breathing and hypertension. N Engl J Med 2000; 342: 1378-1384.

15 Arias MA, García-Río F, Alonso-Fernández A, et al. Obstructive sleep apnea syndrome affects left ventricular diastolic function: effects of nasal continuous positive airway pressure in men. Circulation 2005; 112: 375-383.

16 Oliveira W, Campos O, Cintra F, et al. Impact of continuous positive airway pressure treatment on left atrial volume and function in patients with obstructive sleep apnoea assessed by real-time threedimensional echocardiography. Heart 2009; 95: 1872-1878.

17 Shivalkar B, Van de Heyning C, Kerremans M, et al. Obstructive sleep apnea syndrome: more insights on structural and functional cardiac alterations, and the effects of treatment with continuous positive airway pressure. J Am Coll Cardiol 2006; 47: 1433-1439.

18 Alchanatis M, Tourkohoriti G, Kosmas EN, et al. Evidence for left ventricular dysfunction in patients with obstructive sleep apnoea syndrome. Eur Respir J 2002; 20: 1239-1245.

19 Bayram NA, Ciftci B, Durmaz T, et al. Effects of continuous positive airway pressure therapy on left ventricular function assessed by tissue Doppler imaging in patients with obstructive sleep apnoea syndrome. Eur J Echocardiogr 2009; 10: 376-382.

20 Fung JW, Li TS, Choy DK, et al. Severe obstructive sleep apnea is associated with left ventricular diastolic dysfunction. Chest 2002; 121: 422-429.

21 Kraiczi H, Caidahl K, Samuelsson A, et al. Impairment of vascular endothelial function and left ventricular filling: association with the severity of apnea-induced hypoxemia during sleep. Chest 2001; 119: 1085-1091.

22 Sidana J, Aronow WS, Ravipati G, et al. Prevalence of moderate or severe left ventricular diastolic dysfunction in obese persons with obstructive sleep apnea. Cardiology 2005; 104: 107-109.

23 Niroumand M, Kuperstein R, Sasson Z, et al. Impact of obstructive sleep apnea on left ventricular mass and diastolic function. Am J Respir Crit Care Med 2001; 163: 1632-1636.

24 Schulz R, Blau A, Börgel J, et al. Sleep apnoea in heart failure. Eur Respir J 2007; 29: 1201-1205.

25 Pritchett AM, Jacobsen SJ, Mahoney DW, et al. Left atrial volume as an index of left atrial size: a population-based study. J Am Coll Cardiol 2003; 41: 1036-1043.

26 Devereux RB, Alonso DR, Lutas EM, et al. Echocardiographic assessment of left ventricular hypertrophy: comparison to necropsy findings. Am J Cardiol 1986; 57: 450-458.

27 Nagueh SF, Appleton CP, Gillebert TC, et al. Recommendations for the evaluation of left ventricular diastolic function by echocardiography. Eur J Echocardiogr 2009; 10: 165-193.

28 Hedner J, Bengtsson-Boström K, Peker Y, et al. Hypertension prevalence in obstructive sleep apnoea and sex: a populationbased case-control study. Eur Respir J 2006; 27: 564-570.

29 Wachter R, Lüers C, Kleta S, et al. Impact of diabetes on diastolic function in patients with arterial hypertension. Eur J Heart Failure 2007; 9: 469-476.

30 Haruki N, Takeuchi M, Nakai H, et al. Overnight sleeping induced daily repetitive left ventricular systolic and diastolic dysfunction in obstructive sleep apnoea: quantitative assessment using tissue Doppler imaging. Eur J Echocardiogr 2009; 10: 769-775.

31 Redfield MM, Jacobsen SJ, Burnett JC Jr, et al. Burden of systolic and diastolic ventricular dysfunction in the community: appreciating the scope of the heart failure epidemic. JAMA 2003; 289: 194-202.

32 Yaggi HK, Concato J, Kernan WN, et al. Obstructive sleep apnea as a risk factor for stroke and death. N Engl J Med 2005; 353: 2034-2041. 
33 Marin JM, Carrizo SJ, Vicente E, et al. Long-term cardiovascular outcomes in men with obstructive sleep apnoea-hypopnoea with or without treatment with continuous positive airway pressure: an observational study. Lancet 2005; 365: 1046-1053.

34 O'Connor GT, Caffo B, Newman AB, et al. Prospective study of sleep-disordered breathing and hypertension: the Sleep Heart Health Study. Am J Respir Crit Care Med 2009; 179: 1159-1164.

35 Baguet JP, Barone-Rochette G, Levy P, et al. Left venricular diastolic dysfunction is linked to severity of obstructive sleep apnoea. Eur Respir J 2010; 36: 1323-1329.

36 Sharma SK, Agrawal S, Damodaran D, et al. CPAP for the metabolic syndrome in patients with obstructive sleep apnea. $N$ Engl J Med 2011; 365: 2277-2286.

37 Lanfranchi PA, Somers VK, Braghiroli A, et al. Central sleep apnea in left ventricular dysfunction: prevalence and implications for arrhythmic risk. Circulation 2003; 107: 727-732.

$38 \mathrm{Kim} \mathrm{SH}, \mathrm{Cho}$ GY, Shin C, et al. Impact of obstructive sleep apnea on left ventricular diastolic function. Am J Cardiol 2008; 101: 1663-1668.
39 Bitter T, Faber L, Hering D, et al. Sleep-disordered breathing in heart failure with normal left ventricular ejection fraction. Eur J Heart Fail 2009; 11: 602-608.

40 Chan J, Sanderson J, Chan W, et al. Prevalence of sleep-disordered breathing in diastolic heart failure. Chest 1997; 111: 1488-1493.

41 Colish J, Walker JR, Elmayergi N, et al. Obstructive sleep apnea: effects of continuous positive airway pressure on cardiac remodeling as assessed by cardiac biomarkers, echocardiography, and cardiac MRI. Chest 2012; 141: 674-681.

42 Ficker JH, Wiest GH, Wilpert J, et al. Evaluation of a portable recording device (Somnocheck) for use in patients with suspected obstructive sleep apnoea. Respiration 2001; 68: 307-312.

43 Quintana-Gallego E, Villa-Gil M, Carmona-Bernal C, et al. Home respiratory polygraphy for diagnosis of sleepdisordered breathing in heart failure. Eur Respir J 2004; 24: 443-448.

44 Calleja JM, Esnaola S, Rubio R, et al. Comparison of a cardiorespiratory device versus polysomnography for diagnosis of sleep apnoea. Eur Respir J 2002; 20: 1505-1510. 